$B J M G 10 / 2(2007) 23-28$

$10.2478 / \mathrm{v} 10034-008-0003-3$

ORIGINAL ARTICLE

\title{
MOLECULAR ANALYSIS OF A FAMILY WITH CONGENITAL ADRENAL HYPERPLASIA- GENOTYPE/PHENOTYPE DISCREPANCY
}

\author{
Anastasovska V, Kocova M*
}

*Corresponding Author: Professor Dr. Mirjana Kocova, University Pediatric Clinic, Medical Faculty, Vodnjanska 17, 1000 Skopje, Republic of Macedonia; Tel.: +389-2-3111713; Fax: +389-2-3229-027; E-mail:mirjanakocova@yahoo.com

\begin{abstract}
Congenital adrenal hyperplasia $(\mathrm{CAH})$ is a common autosomal recessive disease with a variable clinical presentation caused by a spectrum of different mutations. A significant association of genotype with phenotype has been reported.

The molecular analysis of a girl with a mild form of $\mathrm{CAH}$ presenting with precocious pubarche, confirmed that she was heterozygous for two mutations of the CYP21 gene (exon 1, codon 30/exon 8, codon 318 ). Her mother was homozygous for the codon 30 mutation and her father was homozygous for the codon 318 mutation. The only anomaly in the parents was a difficulty in conceiving. The molecular analysis of this family confirmed the variability of presentation in carriers of different mutations, which caused difficulties in decisions about the timing of therapy and in genetic counseling.
\end{abstract}

Key words: Congenital adrenal hyperplasia (CAH), CYP Mutations, Phenotype

\section{INTRODUCTION}

Congenital adrenal hyperplasia (CAH) is a heterogenous group of hereditary autosomal recessive disorders characterized by deficient synthesis

University Pediatric Clinic, Medical Faculty,

Skopje, Republic of Macedonia of adrenal steroid hormones. It is the most frequent cause of adrenal insufficiency and ambiguous genitalia in infancy. The disease is caused, in most cases (more than 90\%), by defects in the gene coding for steroid 21 hydroxylase, CYP21 [1,2].

Classical forms of CAH can manifest as lethal mineralocorticoid and cortisol insufficiency, or as a simple virilation. The late onset form presents in girls and young women with only hirsutism and oligoamenorrhea, whereas cryptic forms have no clinical symptoms and are detected only when family studies are performed [3-7]. Such heterogeneity has imposed difficult questions about the genetic background of the disease.

The incidence of different forms of the disease varies in different populations. Throughout Caucasian and Oriental populations the average incidence is 1:15,000 newborns. In general, three-quarters of the affected children have the salt-wasting form and only $20 \%$ have simple virilization.

The CYP21 gene is frequently modified through mutations and conversions from the very homologous pseudogene CYP21P [8-10]. A strong relation of genotype to phenotype exists. Aberrant splicing in intron 2 at nucleotide (nt) 656, an 8 bp frameshift deletion at codons 111-113, a thymine insertion at codon 306 , a nonsense mutation at codon 318 , and a single base substitution at codon 356 , result in a complete inactivation of 21-hydroxylase and are found in the severe classical form of salt-wasting disease [3-5]. A 
single base change in exon 1 at codon 30 , in exon 3 at codon 105, in exon 7 at codon 281, and in exon 10 at codon 453, are associated with the milder non classical form of $\mathrm{CAH}$, in which there is only partial loss of 21-hydroxylase activity $[4,6]$. The simple virilization found in some CAH patients is associated with a mutation in exon 4 at codon 172, which abolishes 21-hydroxylase activity $[4,7]$. Combination of these mutations can cause different phenotypes [11,12].

We present a young girl who had a combination of severe and mild mutations and presented as simple virilization and whose parents have $\mathrm{CAH}$ which manifested only as a difficulty to conceive.

\section{CASE REPORT}

The patient was a 5 and a half-year-old girl, born as the first child of healthy young parents who had been. treated for sterility for 9 years. She was conceived by in vitro fertilization. No data were available about the cause of infertility. Mother did not have any health problems. She did not have hirsutism, nor precocious puberty. The father was a healthy individual, and was told that he had a poor sperm count during the sterility treatment. Both parents are Macedonians of Slavic descent. The birth weight of the girl was 3,000 g and birth length was $50 \mathrm{~cm}$. She was developing normally. At the age of 5 years, pubic hair appeared and she was referred to the hospital for hormonal work-up. Clinical examination revealed a healthy and well-developed female child with pubic hair P2 according to Tanner [13]. The clitoris was enlarged (stage 2 according to the Prader classification of sexual ambiguity) [14]. No other pubic signs or abnormalities were detected. Her growth was at $90 \%$ o, and her weight at $75 \%$ o according to the Tanner-Whitehouse charts [15]. Bone age was advanced and was 9.5 years at diagnosis [+2.5 standard deviation (SD)]. 17-OH Progesterone was $4.0 \mathrm{ng} / \mathrm{mL}$ (within the normal range), but after stimulation with ACTH, reached $257 \mathrm{nmol} / \mathrm{L}$ at 2 hours (normal peak up to $121 \mathrm{nmol} / \mathrm{L}$ ). The testosterone level was $2.51 \mathrm{nmol} / \mathrm{L}$ (normal range 0.19-2.67 nmol/L), and Dihydroepiandroster-one-S levels were normal.

She was diagnosed with a simple virilizing form of CAH. Treatment with hydrocortisone (7.5 $\mathrm{mg}$ twice daily divided) stopped the development of pubic hair, and improved the height/bone age ratio.
Three years after diagnosis she grew at $75 \% \mathrm{o}$ and her pubic hair is $\mathrm{P} 3$ according to Tanner.

\section{MATERIALS AND METHODS}

Blood samples for molecular diagnosis of CYP21 mutations were obtained from the girl and both parents. Genomic DNA was isolated from leukocytes using the standard proteinase K/SDS digestion-phenol/ chloroform extraction-ethanol precipitation method.

Because of the high homology between the CYP21 and CYP21P genes (98\% of nt sequences), a strategy to amplify the CYP21 gene differentially was used, following the polymerase chain reaction (PCR) conditions described in Gene Amp XL (Extra Long) PCR Kit (Applied BioSystems, Foster City, CA, USA). The primary PCR product was used as a template for secondary PCR amplification. Using the amplification-created restriction site (ACRS) approach for direct detection of mutations [16], a secondary PCR was then performed using a panel of primers specific for 11 known CAH mutations, according to the method previously described [17].

Following the secondary ACRS PCR, $3 \mu \mathrm{L}$ of the PCR product was incubated, overnight at $37^{\circ} \mathrm{C}$, with 5 to10 units of a specific restriction enzyme (Table 1 ), then analyzed by $2 \%$ agarose gel electrophoresis. Subsequent restriction analyses allowed the detection and the determination of the zygosity of the mutation analyzed.

\section{RESULTS AND DISCUSSION}

To distinguish between the inactive pseudogene (CYP21P) and the active gene (CYP21), two pairs of oligonucleotide primers (21AF/AR and 21BF/BR, respectively) were used for differential amplification of these genes as previously described [17]. A $3.2 \mathrm{~kb}$ product was detected (Figure 1).

The PCR products generated from CYP21P and CYP21 were distinguishable by digestion with the restriction enzyme EcoRI, which for the CYP21P produced three fragments $(0.5,0.6$ and $2.2 \mathrm{~kb})$, whereas for the active CYP21 gene produced only two fragments $(1.0$ and $2.2 \mathrm{~kb})$. The primary PCR products of the CYP21 gene were subjected to locus analysis by using secondary ACRS PCR (Table 1).

Two of the $11 \mathrm{CAH}$ mutations analyzed were detected in the proband and in her parents (Figure 2). 
Table 1. Amplification-created restriction site detection of mutations in the CYP21 genes

\begin{tabular}{|c|c|c|c|c|c|}
\hline \multirow{2}{*}{ Primer Pair } & Mutational Allele & \multicolumn{2}{|c|}{ Restriction Site } & \multicolumn{2}{|c|}{ Fragment Size (bp) } \\
\cline { 2 - 5 } & & Natural $^{\mathbf{a}}$ & Created $^{\text {b }}$ & Normal & Mutant \\
\hline C1N/C2 & Exon1, codon 30 & - & PstI & 195 & $164+31$ \\
\hline C3B/C4A & Intron 2, nt 656 & - & SacI & 115 & $85+30$ \\
\hline C3B/C4A & Exon 3, codons 111-113 & - & RsaI & 115 & $89+26$ \\
\hline C5/C6 & Exon 4, codon 172 & - & MseI & 148 & $118+30$ \\
\hline C7D1/C8 & Exon 6, codon 236 & - & MboI & $114+26$ & 140 \\
\hline C7E/C8 & Exon 6, codon 237 & - & TaqI & 140 & $116+24$ \\
\hline C7C1/C8 & Exon 6, codon 239 & - & MseI & 140 & $110+30$ \\
\hline C9/C10-1 & Exon 7, codon 281 & ApaLI & - & $116+101$ & 213 \\
\hline C9A/C9B & Exon 7, codon 306 & - & $M w o I$ & $123+34$ & 157 \\
\hline C11/C12 & Exon 8, codon 318 & $P s t I$ & - & $146+51$ & 197 \\
\hline C11/C12 & Exon 8, codon 356 & - & $M s c I$ & 197 & $167+30$ \\
\hline
\end{tabular}

${ }^{a}$ Natural: in two cases, the mutations had naturally created recognition sites for direct restriction detection.

${ }^{\mathrm{b}}$ Created: region-specific primers for nine known mutation loci were designed that would lead to the creation of new restriction recognition sites at these known mutation sites on secondary amplification.
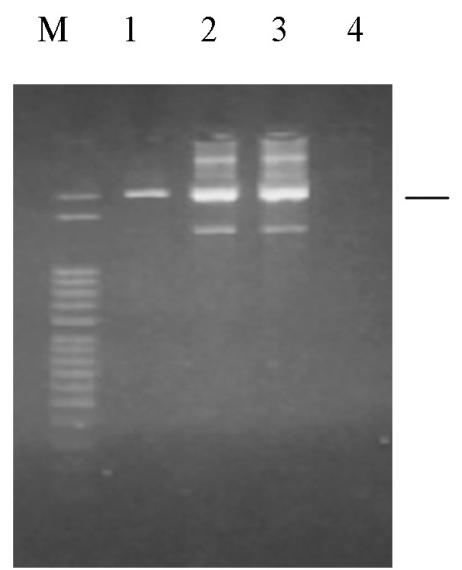

$3.2 \mathrm{~kb}$

Figure 1. Differential amplification of the active CYP21 gene. Lanes 1, 2, 3: A $3.2 \mathrm{~kb}$ product of the active CYP21 gene; Lane 4: blank; M: marker (50 bp).

The proband was heterozygous for two mutations, one in exon 1 (at codon 30, which is considered to be a mild mutation), the second in exon 8 (at codon 318 , considered to be a severe mutation). This genotype usually produces a moderate phenotype of the disease. The mother was homozygous for the mutation exon 1 , codon $30 \quad$ exon 8, codon 318

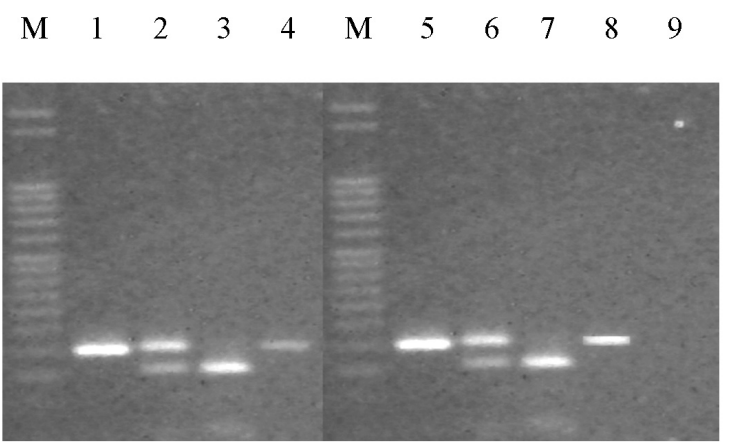

Figure 2. Mutations in exon $1 /$ codon 30 and exon $8 /$ codon 318 of the CYP21 gene. M: marker (50 bp); lanes 1 and 5: PCR II product; lanes 2 and 6: patient; lanes 3 and 7: mother; lanes 4 and 8: father; lane 9: blank.

in exon 1 (at codon 30) and only had difficulty in conceiving. The father was homozygous for the mutation in exon 8 (at codon 318), a nonsense mutation usually associated with severe salt-wasting, and only suffered from difficulty in fathering a child, which is an unusual presentation of the disease. These results 
indicated that the proband inherited the mutation in exon 1 at codon 30 from her mother and that in exon 8 at codon 318 from her father.

A clear genotype/phenotype correlation in $\mathrm{CAH}$ patients has been established by many large studies $[18,19]$. Classification of mutations into severe, moderate and mild, and their combination, can predict the severity of the clinical presentation in approximately $79 \%$ of patients [18]. However, there is a high degree of overlap between moderate and mild forms. The Pro30Leu anomaly, usually associated with a simple virilizing form of the disease, is one of the less frequent mutations, and has also been described in non classical mild forms of the disease [19]. Our patient carried one severe mutation (codon 318) and one moderate mutation (codon 30 ), and presented with a mild form of late onset and mild evolution. From her genotype, we would expect a more severe form of the disease with earlier presentation and more severe virilization. Treatment was effective in the progression of the puberty and bone maturation.

Both parents are also CAH patients on the basis of genotype. The mother, who was homozygous for the mild mutation (codon 30), did not have symptoms of the disease until the age of conception, when she was unable to conceive and was treated for sterility. No history of early virilization was present. Her clinical presentation is consistent with the genotype, although earlier presentation would have been expected.

The father, homozygous for the severe nonsense mutation (codon 318), which usually presents with a salt-wasting form accompanied by precocious puberty and frequently by sterility. Although improvement of salt-wasting has been shown with age in some studies [19], we were not able to find another published case of homozygosity for the nonsense mutation who survived childhood without therapy. All inquiries about the father's early puberty were also negative. Thus, his only presentation was a poor sperm count. De novo recombination and unequal crossover involving CYP21 have been documented in sperm [19], however, there is no evidence of this process in our patient. It is impossible to postulate which parent contributed most to the failure to conceive a child spontaneously.

One might speculate that there may be additional 21-hydroxylase activity not encoded by the CYP21 gene that contributes to the moderate clinical presen- tation. Modifying genes and transcription abnormalities of the CYP21 gene could also be involved.

Genotype/phenotype discrepancies pose difficulties, especially for genetic counseling of families. An extended pedigree with genotyping of more members of this family might be helpful in the future.

In conclusion, based on the genotype, a more severe phenotype would have been expected in the mother, the father and the child. It is possible that some protective mechanisms, yielding higher 21-hydroxylase enzyme activity, have been transmitted to the child from both parents. Further analyses of the enzyme activity are necessary to elucidate the unusual clinical presentation and genotype/phenotype discrepancies.

\section{REFERENCES}

1. Arlt W, Walker EA, Draper N, Ivison HE, Ride JP, Hammer F, Chalder SM, Borucka-Mankiewicz M, Hauffa BP, Malunowicz EM, Stewart PM, Shackleton CHL. Congenital adrenal hyperplasia caused by mutant P450 oxidoreductase and human androgen synthesis: analytical study. The Lancet 2004; 363(9427): 2128-2135.

2. Morel Y, Miller WL. Clinical and molecular genetics of congenital adrenal hyperplasia due to 21-hydroxylase deficiency. Adv Hum Genet 1991; 20: $1-68$.

3. New MI. 21-hydroxylase deficiency congenital adrenal hyperplasia. J Steroid Biochem Molec Biol 1994; 48(1): 15-22.

4. Higashi Y, Hiromasa T, Tanae A, Miki T, Nakura J, Kondo T, Ohura T, Ogawa E, Nakayama K, Fujii-Kuriyama Y. Effects of individual mutations in the P-450 (C21) pseudogene on the P450 (C21) activity and their distribution in the patient genomes of congenital steroid 21-hydroxylase deficiency. J Biochem 1991; 109(4): 638-644.

5. Mornet E, Couillin P, Kuttenn F, Raux MC, White PC, Cohen D, Boué A, Dausset J. Distribution of deletions and seven point mutations on CYP21B genes in three clinical forms of steroid 21-hydroxylase deficiency. Am J Hum Genet 1991; 48(1): 79-88.

6. Tusie-Luna MT, Speiser PW, Dumic M, New MI, White PC. A mutation (Pro-30 to Leu) in CYP21 represents a potential nonclassic steroid 21-hydroxylase deficiency allele. Mol Endocrinol 1991; 5(5): 685-692. 
7. Chiou Sh-H, Hu M-Ch, Chung B-Ch. A missense mutation at Ile ${ }^{172} \rightarrow$ Asn or Arg $^{356} \rightarrow$ Trp causes steroid 21-hydroxylase deficiency. J Biol Chem 1990; 265(6): 3549-3552.

8. Higashi Y, Yoshioka H, Yamane M, Gotoh O, Fujii-Kuriyama Y. Complete nucleotide sequence of two steroid 21-hydroxylase genes tandemly arranged in human chromosome: a pseudogene and a genuine gene. Proc Natl Acad Sci USA 1986; 83(9): 2841-2845.

9. White PC, New MI, Dupont B. Sructure of human steroid 21-hydroxylase genes. Proc Natl Acad Sci USA 1986; 83(14): 5111-5115.

10. Rodrigues NR, Dunham I, Yu CY, Carroll MC, Porter RR, Compbell RD. Molecular characterization of the HLA-linked steroid 21-hydroxylase B gene from an individual with congenital adrenal hyperplasia. EMBO J 1987; 6(6): 1653-1661.

11. Balsamo A, Cacciari E, Baldazzi L, Tartaglia L, Cassio A, Mantovani V, Piazzi S, Cicognani A, Pirazzoli P, Mainetti B, Zappulla F. CYP21 analysis and phenotype/genotype relationship in the screened population of the Italian Emilia-Romana region. Clin Endocrinol 2000; 53(1): 117-125.

12. Charmandari E, Eisenhofer G, Mehlinger SL, Carlson A, Wesley R, Keil MF, Chrousos GP, New MI, Merke DP. Adrenomedullary function may predict phenotype and genotype in classic 21-hydroxylase deficiency. J Clin Endocrinol Metab 2002; 87(7): 3031-3037.

13. Tanner JM. Growth at Adolescence, with a General Consideration of the Effects of Hereditary and Environmental Factors Upon Growth and Maturation From Birth to Maturity, 2nd ed. Oxford: Blackwell Scientific Publications, 1962.

14. Prader A, Illig R, Zachmann M. Prenatal LH-deficiency as possible cause of male pseudohermaphroditism, hypospadias, hypogenitalism and cryptorchidism. Proceedings of the European Society of Paediatric Endocrinology, Rotterdam, The Netherlands. Paediatr Res 1976; 10: 883.

15. Tanner JM, Whitehouse RH, Takaishi M. Standards from birth to maturity for height, weight, height velocity and weight velocity. British children. Part II. Arch Dis Child 1966; 41(220): 613-635.

16. Haliassos A, Chomel JC, Tesson L, Baudis M, Kruh J, Kaplan JC, Kitzis A. Modification of enzymatically amplified DNA for the detection of point mutations. Nucleic Acids Res 1989; 17(9): 3606.

17. Lee HH, Chao HT, Ng HT, Choo KB. Direct molecular diagnosis of CYP21 mutations in congenital adrenal hyperplasia. J Med Gen 1996; 33(5): 371-375.

18. Krone N, Braun A, Roscher AA, Knorr D, Schwarz HP. Predicting phenotype in steroid 21-hydroxylase deficiency? Comprehensive genotyping in 155 unrelated, well defined patients from southern Germany. J Clin Endocrinol Metab 2000; 85(3): 1059-1065.

19. White OC, Speiser PW. Congenital adrenal hyperplasia due to 21-hydroxylase deficiency. Endocr Rev 2000; 21(3): 245-291 
